\title{
Impact of the European Board of Paediatric Surgery Examination on Career Progression: a cross- sectional survey study
}

\section{Takafumi Kawano}

Kagoshima Daigaku

Oliver Muensterer

Johannes Gutenberg Universitat Mainz Universitatsbibliothek Mainz

Rosemary MacKenzie

NHS Greater Glasgow and Clyde

Salvatore Cascio ( $\square$ salvatorecascio@doctors.org.uk)

Our Lady's Children's Hospital

Research article

Keywords:

Posted Date: April 1st, 2020

DOI: https://doi.org/10.21203/rs.3.rs-20526/v1

License: (9) This work is licensed under a Creative Commons Attribution 4.0 International License. Read Full License 


\section{Abstract}

Background: The two-part examination of the European Board in Pediatric (EBPS) Surgery was established in 2005 with the aim of ensuring harmonization of standards of training in Europe. The aim of this study was to assess the impact of the examination on career progression using a validated questionnaire. Methods: Between 2005 and 2016 a total of 227 candidates successfully passed part 2 of the EBPS examination. Of these, we were able to successfully contact 160 candidates by email and ask them to complete a validated online questionnaire,the Career Success Scale (CSS). Eighty-five candidates answered and 49 completed all items of the questionnaire (recall of 31\%). Information on demographics, work environment, publication output, and self-reflecting personal opinion on the impact of EBPS certification on career progression was also queried. Results: A recall of $31 \%$ was obtained (49 out of 160). Most respondents were male (82\%), had published scientific manuscripts in peer-reviewed journals (93\%), were actively presenting at conferences (96\%), and believed that passing the examination helped them reach their career goals (61\%). Involvement in multicenter studies was reported by $51 \%$ of respondents, $16 \%$ had obtained research awards, $16 \%$ received scholarships, and $9 \%$ reported research as their principal activity. Conclusion: Candidates who passed the European Board Exam reported a high level of academic activity. Most of them believed that passing the exam had a positive effect on their career development.

\section{Background}

The European Board of Pediatric Surgery (EBPS) was established in the 1990s with the aim of ensuring harmonization of standards of training in Europe within the framework of the Union Europeenne des Medecins Specialistes (UEMS) [1]. The first EBPS examination was held in Paris in 1999, which consisted of five live oral examinations each lasting $35 \mathrm{~min}$, including a clinical exam on one major topic and a variety of smaller cases, as well as an oral exam in neonatal surgery, genitourinary surgery, and general pediatric surgery. From 2005, the examination process changed to the current two-part format: Part 1 made of 100 written multiple-choice type questions and Part 2 which consists of a clinical examination and three oral examination. In 2019, the traditional format delineated above was changed to an OSCE (objective structured clinical examination), in which the candidates must solve standardized patient scenarios that include a history, clinical pictures, as well as imaging and laboratory information [2].

Since 2005, more than 250 candidates have passed the EBPS examination [3]. They were trained in many various European and non-European countries, indicating that the exam has gained international acceptance. It therefore currently serves as the only worldwide universal benchmark for pediatric surgical competency.

Until now, the significance of the exam for the examinee has not been systematically assessed. The aim of this study was therefore to assess the impact of the EBPS examination from the point of career progression using a validated web-based questionnaire. 


\section{Methods}

Candidates who passed the EBPS Examination from 2005 to 2016 were contacted by email and asked to complete an online anonymous questionnaire (Survey Monkey, San Mateo, CA, USA). The questionnaire was constructed based on the validated Career-Success Scale (CSS), which contains seven items concerning scientific activities (such as number of research projects, lectures, publications, grants, scholarship, awards). In addition three questions were added for the purpose of this study (Questions 13 , Table 1). CSS scores may range from 0 (no career advancement) to 11 (very high career advancement). A detailed overview of the questionnaire and its items are found in Table 1.

Table 1

Online questionnaire based on the Career-Success-Scale (CSS) used in this study

\begin{tabular}{|c|c|c|}
\hline 1 & What is your gender? & $\begin{array}{l}\square \text { Male } \\
\square \text { Female }\end{array}$ \\
\hline 2 & What setting do you mainly work in? & $\begin{array}{l}\square \text { Academic } \\
\text { institution } \\
\text { (university) } \\
\square \text { Public hospital } \\
\square \text { Private practice }\end{array}$ \\
\hline 3 & $\begin{array}{l}\text { Do you think that undertaking the EBPS exam helped to achieve your } \\
\text { career goals? }\end{array}$ & $\begin{array}{l}\square \text { Yes } \\
\square \text { No }\end{array}$ \\
\hline 4 & $\begin{array}{l}\text { Looking at your career, have you made any lectures or talks held at } \\
\text { conferences and } \\
\text { scientific meetings? }\end{array}$ & $\begin{array}{l}\square \text { Yes } \\
\square \text { No } \\
\text { (if yes, how many? } \\
\end{array}$ \\
\hline 5 & $\begin{array}{l}\text { Looking at your career have you made any publications (original papers } \\
\text { with peer review, first authorship or co-authorship)? }\end{array}$ & $\begin{array}{l}\square \text { Yes } \\
\square \text { No } \\
\text { (if yes, how many? } \\
\end{array}$ \\
\hline 6 & $\begin{array}{l}\text { Looking at your career have you made any collaboration in a larger } \\
\text { research project? }\end{array}$ & $\begin{array}{l}\square \text { Yes } \\
\square \text { No }\end{array}$ \\
\hline 7 & Looking at your career is research your principal activity? & $\begin{array}{l}\square \text { Yes } \\
\square \text { No }\end{array}$ \\
\hline 8 & Looking at your career did you have any scholarship awarded? & $\begin{array}{l}\square \text { Yes } \\
\square \text { No }\end{array}$ \\
\hline 9 & Looking at your career did you gain third parties fund for research? & $\begin{array}{l}\square \text { Yes } \\
\square \text { No }\end{array}$ \\
\hline 10 & Looking at your career did you obtain any research awards & $\begin{array}{l}\square \text { Yes } \\
\square \text { No }\end{array}$ \\
\hline
\end{tabular}

All data was analyzed statistically by current work setting and whether respondents perceived passing the EBPS examination as valuable for career progression. Scaled values were presented as means and 
standard deviations (STD). Numerical values were compared using the Chi-square test, continuous variables were compared using the t-test.

\section{Results}

A total of 227 candidates successfully passed part 2 of the EBPS examination over the 12 year study period (2005-2016). Of these, we were able to successfully contact by email 160 candidates and ask them to complete an online questionnaire. Of these 85 candidates answered and 49 completed all items of the questionnaire (recall of $31 \%$ ).

The results of the survey are shown in Table 2. Most candidates were male (31, versus 18 females) and worked in public hospitals (51\%, versus $37 \%$ in academic centers). Almost two thirds (61\%) subjectively thought that passing the EBPS examination helped to achieve their career goals.

Table 2

Survey results

\begin{tabular}{|c|c|c|c|}
\hline 1 & Gender (Male:Female) & \multicolumn{2}{|c|}{41 (83.7\%): 6 (12.2\%) } \\
\hline 2 & Work Place & \multicolumn{2}{|c|}{$\begin{array}{l}\text { Academic: } 18(36.7 \%) \\
\text { Public: } 25(51.0 \%) \\
\text { Private: } 6(12.2 \%)\end{array}$} \\
\hline 3 & EBPS Examination helped? & Yes & $30(61.2 \%)$ \\
\hline 4 & Lecture or Talks & $\begin{array}{l}\text { None } \\
1-3 \\
4-50\end{array}$ & $\begin{array}{l}2(4.1 \%) \\
8(16.3 \%) \\
39(79.6 \%)\end{array}$ \\
\hline 5 & Publications & $\begin{array}{l}\text { None } \\
1 \\
2-3 \\
4 \text { and more }\end{array}$ & $\begin{array}{l}8(16.3 \%) \\
3(6.1 \%) \\
5(10.2 \%) \\
33(67.3 \%)\end{array}$ \\
\hline 6 & Collaboration research project & Yes & $19(63.3 \%)$ \\
\hline 7 & Research as principle activity & Yes & $4(13.3 \%)$ \\
\hline 8 & Scholarship awarded & Yes & $4(13.3 \%)$ \\
\hline 9 & Third-party funding & Yes & $3(10.0 \%)$ \\
\hline 10 & Research awards & Yes & $5(16.6 \%)$ \\
\hline
\end{tabular}

Most respondents (84\%) had written scientific publications, and almost all (96\%) had given talks or lectures at conferences. Roughly half (51\%) were involved in larger research projects, and 8 of 49 respondents (16\%) had received research awards more than once. Only 5 of 49 respondents had gained third party funding for research, including pediatric surgical research, and only $16 \%$ were awarded scholarships. Four candidates claimed that research was their principal activity. 
The distribution of the CSS in our study sample is seen in Fig. 1. The mean score of all candidates was 5.2, with a standard deviation of 2.2. CSS scores were significantly higher for successful EBPS Part 2 graduates employed at academic institutions (university hospitals) compared to those in public hospitals (Fig. 2).

When comparing the data between those candidates who subjectively thought that the EBPS examination helped them achieve their career goals or not, there was no significant difference regarding gender or employment setting. However, those that were actively giving talks at meetings and conferences, and those that were collaborating in larger research projects were significantly more likely to report that passing the EBPS examination helped them in their career advancement (Table 3). Also, there was a trend towards higher CSS scores ( $5.70+/$-STD 1.99 versus $4.53+/$-STD 2.30 [p $=0.09])$ in the group that claimed passing the EBPS to have a positive effect on their career.

Table 3

Comparison of individual surveyed items by the candidates' positive or negative impact on career perception

\begin{tabular}{|c|c|c|c|}
\hline & \multicolumn{2}{|c|}{ EBPS helped to achieve the career goal? } & \multirow[t]{2}{*}{ p value } \\
\hline & Yes $(n=30)$ & No $(n=19)$ & \\
\hline Gender $(M: F)$ & $24: 6$ & $15: 4$ & 0.60 \\
\hline Work place & $\begin{array}{l}\text { Academic : } 13 \\
\text { Public: } 13 \\
\text { Private : } 4\end{array}$ & $\begin{array}{l}\text { Academic: } 5 \\
\text { Public: } 12 \\
\text { Private : } 2\end{array}$ & 0.20 \\
\hline Lecture or Talks & Yes $=28(93.3 \%)$ & Yes $=13(68.4 \%)$ & 0.03 \\
\hline Publications & Yes $=28(93.3 \%)$ & Yes = $19(100.0 \%)$ & 0.37 \\
\hline Collaboration in a larger research project & Yes $=19(63.3 \%)$ & Yes $=4(21.1 \%)$ & 0.004 \\
\hline Research as principle activity & Yes $=4(13.3 \%)$ & Yes $=3(15.8 \%)$ & 0.56 \\
\hline Scholarship awarded & Yes $=4(13.3 \%)$ & Yes $=2(10.5 \%)$ & 0.57 \\
\hline Third-party funding & Yes $=3(10.0 \%)$ & Yes $=2(10.5 \%)$ & 0.65 \\
\hline Research awards & Yes $=5(16.6 \%)$ & Yes $=3(15.8 \%)$ & 0.63 \\
\hline CSS score & $5.70+-1.99$ & $4.53+-2.30$ & 0.09 \\
\hline
\end{tabular}

\section{Discussion}

Starting in the mid twentieth century, pediatric surgery as a specialty became gradually recognized in many countries around the world. Ever since, pediatric surgeons have differentiated themselves from adult general surgeons and organ specialists, maintaining a relatively large spectrum of indications, 
including neonatal surgery, general pediatric surgery, pediatric urology, pediatric trauma and burn care, as well as many other fields. Consequently, pediatric surgeons around the world had to establish comprehensive training systems that ensured competency. Systems developed differently from country to country, but with increasing globalism and the creation of the European Union, there was an impetus to create a certification system that would ensure a set benchmark for pediatric surgical knowledge and competency. This was the driving force behind the implementation of an international European pediatric surgical examination.

The EBPS was therefore established in the latter part of the 1990s with the aim of ensuring harmonization of standards of training in Europe within the framework of the UEMS [2]. The exam can be taken by candidates who have already passed the EBPS part one examination and have completed an approved Pediatric Surgical Training scheme. For countries which have no official structured training program, the candidate must show evidence of at least 5 year of pediatric surgery experience in a recognized training insitution and show evidence of operative experience (personal log book or operative summary signed by their training supervisor).

To standardize the quality of pediatric surgeon board in Europe, the UEMS Section of Pediatric Surgery designed and published a European syllabus for pediatric surgical training in 2009 [5]. This syllabus was revised and new European training requirements were adopted in 2014 with the goal of "harmonizing the training programs in pediatric surgery among different European countries". However, there remains a lack of data on the real, actual training conditions within the European national associations of pediatric surgery. In 2016 a questionnaire survey of Executive Committee of UEMS Section of Pediatric Surgery presented data from 29 of 37 national associations, revealing that a uniform training schedule in pediatric surgery has not been formulated or achieved within Europe so far [6]. Only general pediatric surgery and newborn surgery are included in the core pediatric surgical training uniformly across all countries and training is provided according to historical developments on the local and national regulations. They concluded that this situation mandated an urgent attempt to harmonize both training curricula and final examinations at a European level. Although there are so many problems to resolve for harmonizing pediatric surgical training, the EBPS is one of the sentinel agencies key to this endeavor. However, although it has been more than 20 years since the first EBPS exam was held, only slightly more than $50 \%(15 / 28)$ of the European countries have some kind of recognition [6], and it is legally currently only in Turkey as an exit examination to practice pediatric surgery. Interestingly, Turkey is not part of the European Union at this time.

From the start, the EBPS examination contrasted itself from other board examinations, such as the Pediatric Surgery Qualifying Exam by the American Board of Surgery, in that it accepted applicants from all over the world, providing that they had met certain predetermined requirements set forth by the UEMS. Actually, in our previous study, we have already shown that Part 2 EBPS graduates trained in 33 different countries, including 12 countries of the European Union [3]. This implies that the EBPS is gradually being recognized internationally as the only universal benchmark exam in pediatric surgery currently being offered. With increasing standardization in the future using validated text-based questions for Part 1 and 
standardized OSCE scenarios for Part 2, we anticipate that this trend will continue and that it will eventually serve as an alternative for or even replace national exit examinations across Europe and beyond. This may foster the international exchange of pediatric surgeons among countries in the future.

In our study, most candidates that had passed Part 2 were under the impression that it helped them with career advancement. Those individuals also had higher Career Success Scale scores. Overall, the cohort was academically highly productive, despite the fact that a minority actually practiced in university hospitals. Also, the mean CSS score of all participants, regardless of whether they perceived the EBPS to be helpful or not, was substantially (threefold) higher than the resulting score of 1.76 +/- STD 2.33 from the cohort of 406 physicians used to validate the CSS the original publication by Buddeberg-Fischer et al. [4].

The CSS is tool that was validated in a prospective Swiss cohort study in a sample of 406 young physicians in their sixth year of residency. It is considered to be a short and reliable instrument to measure career progress by objective criteria [4]. The CSS is based on the premise that research productivity is the most relevant factor for pursuing a relevant medical career. Since the evaluation of career performance in the CSS mainly focuses on research activities, grants, publications, it does not incorporate clinical productivity or reputation. Despite its drawbacks, for lack of an alternative, we considered the CSS the only way to assess career advancement in our cohort.

Interestingly, the mean score the CSS for all candidates in our cohort was much higher than the CSS scores reported previously on young physicians, or boarded women surgeons $[7,8]$. This finding goes hand in hand with the surprisingly high academic publication and presentation activities found in our subjects. Perhaps those pediatric surgeons interested in taking the EBPS are also the ones who are motivated to do research and have higher career aspirations than those who do not wish to sit for the exam. Strangely, however, with regard to the third party funding, we found no differences between those who perceived the EBPS examination to be helpful or not, despite the importance to acquire funding for general career progression [9].

Another important factor positively influencing career advancement is mentorship. It has been described as crucial for personal development, career guidance, career choice and career success in the literature, and a core component to pursue an academic career $[10,11]$. Since EBPS has been around for two decades, older, established EBPS certified surgeons may be inclined to mentor younger EBPS graduates and thus help with building their careers.

Our study has several limitations. Our response rate of $53 \%$ to the on line questionnaire is in line with other similar studies. However, only $58 \%$ of the respondents completed all items of the questionnaire. We believe that this study serves as the basis of future prospective investigations on the impact of passing the EBPS examination. Also, we were unable to include a comparison group. It would be interesting to compare the CSS of those who passed the examination to those who failed it. Motivating those who failed the examination to participate in an online survey may be a challenge, however. 


\section{Conclusion}

The two-part EBPS examination with its fair, reproducible and standardized approach is on its way to become the international benchmark examination in pediatric surgery for candidates from EU and non-EU countries alike. Our survey study demonstrated that most candidates who passed Part 2 of the EBPS examination had the impression that it helped them in their career progression. Although they mostly worked in public hospitals, they on average were highly active academically, publishing articles and giving presentations at conferences. Those that subjectively perceived having passed Part 2 as helpful for their career progression were also more likely to have objectively higher CSS scores, implying that EBPS certification may indeed facilitate career advancement.

\section{Abbreviations}

European Board of Pediatric Surgery (EBPS)

Europeenne des Medecins Specialistes (UEMS)

Objective Structured Clinical Examination (OSCE)

Career-Success Scale (CSS)

\section{Declarations}

\section{Ethics approval and consent to participate}

The on line questionnaire was anonymous, no personal data or identifier were included and formal written or verbal consent was deemed not to be required. The survey was approved by the Examination Committee of the European Board of Pediatric Surgery

\section{Availability of data and material}

All raw data this study is based on is available form the authors by request

\section{Competing interests}

The authors declare that this research was conducted in the absence of any commercial or financial relationships that could be constructed as potential conflict of interest.

\section{Funding}

This study was funded by the respective departments and the European Board of Paediatric Surgery

\section{Authors' contributions}

Takafumi Kawano: writing the manuscript, statistical analysis 
Oliver J. Muensterer: revision of the manuscript, statistical analysis

Rosemary Mackenzie: contacted candidates for the survey, set up the on line survey

Salvatore Cascio: study design with questionnaire, set up the on line survey, revision of the manuscript

\section{Acknowledgements}

The authors wish to thank all the successful candidates of the Examination of the European Board of Pediatric Surgery who participated in this survey.

\section{References}

1. Carachi R: President's Report of the European Board of Paediatric Surgery (EBPS) - The Presidentship of the EBPS has changed. During the last meeting of the UEMS at the 4th EUPSA-Congress in Budapest, Professor Ole Nielsen, Denmark, was elected President for a two y. Eur J Pediatr Surg 2001:11;285-287

2. Union Européenne des médecins spécialistes. European union of medical specialists (UEMS):

Training requirements for the specialty of paediatric surgery. European standards of postgraduate medical specialist training. Available online at https://www.uemspaedsurg.org/downloads/Training_requirements_pediatric_surgery_new.pdf, last accessed 30 November 2019

3. Muensterer OJ, Bronstein ME, Mackenzie R, Snyder CW, Carachi R. Factors associated with passing the European Board of Paediatric Surgery Exam. Pediatr Surg Int. 2015;31:671-676

4. Buddeberg-Fischer B, Stamm M, Buddeberg C, Klaghofer R. Career-success scale - a new instrument to assess young physicians' academic career steps. BMC Health Serv Res. 2008;8:120

5. UEMS Section and Board of Paediatric Surgery, European Paediatric Surgeons' Association: European Syllabus of Paediatric Surgery-ver. 1.2. Available online at http://www.paediatricsurgeryexam.org/index.php/about-ebps/useful-downloads2, last accessed 30 November 2019

6. Schmedding A, Rolle U, Czauderna P. European Pediatric Surgical Training. Eur J Pediatr Surg. 2017;27:245-250

7. Buddeberg-Fischer B, Stamm M, Klaghofer R. Career paths in physicians' postgraduate training - an eight-year follow-up study. Swiss Med Wkly 2010;140:w13056

8. Kaderli R, Muff B, Stefenelli U, Businger A. Female surgeons' mentoring experiences and success in an academic career in Switzerland. Swiss Med Wkly 2011;141:w13233

9. Fortin JM, Currie DJ. Big Science vs. Little Science: How Scientific Impact Scales with Funding. PLoS One. 2013;8:e65263

10. Sambunjak D1, Straus SE, Marusić A. Mentoring in academic medicine: a systematic review. JAMA. 2006;296:1103-1115 
11. Stamm M, Buddeberg-Fischer B. The impact of mentoring during postgraduate training on doctors' career success. Med Educ 2011;45:488-496

12. European Board of Paediatric Surgery, European Pediatric Surgery Association: European Pediatric Surgery In-Training Examination (EPSITE) Reference EPSITE. Available online at http://www.eupsa.info/epsite/, last accessed 30 November 2019

Figures

n Career Success Scale (CSS) scores of successful EBPS Part 2 candidates

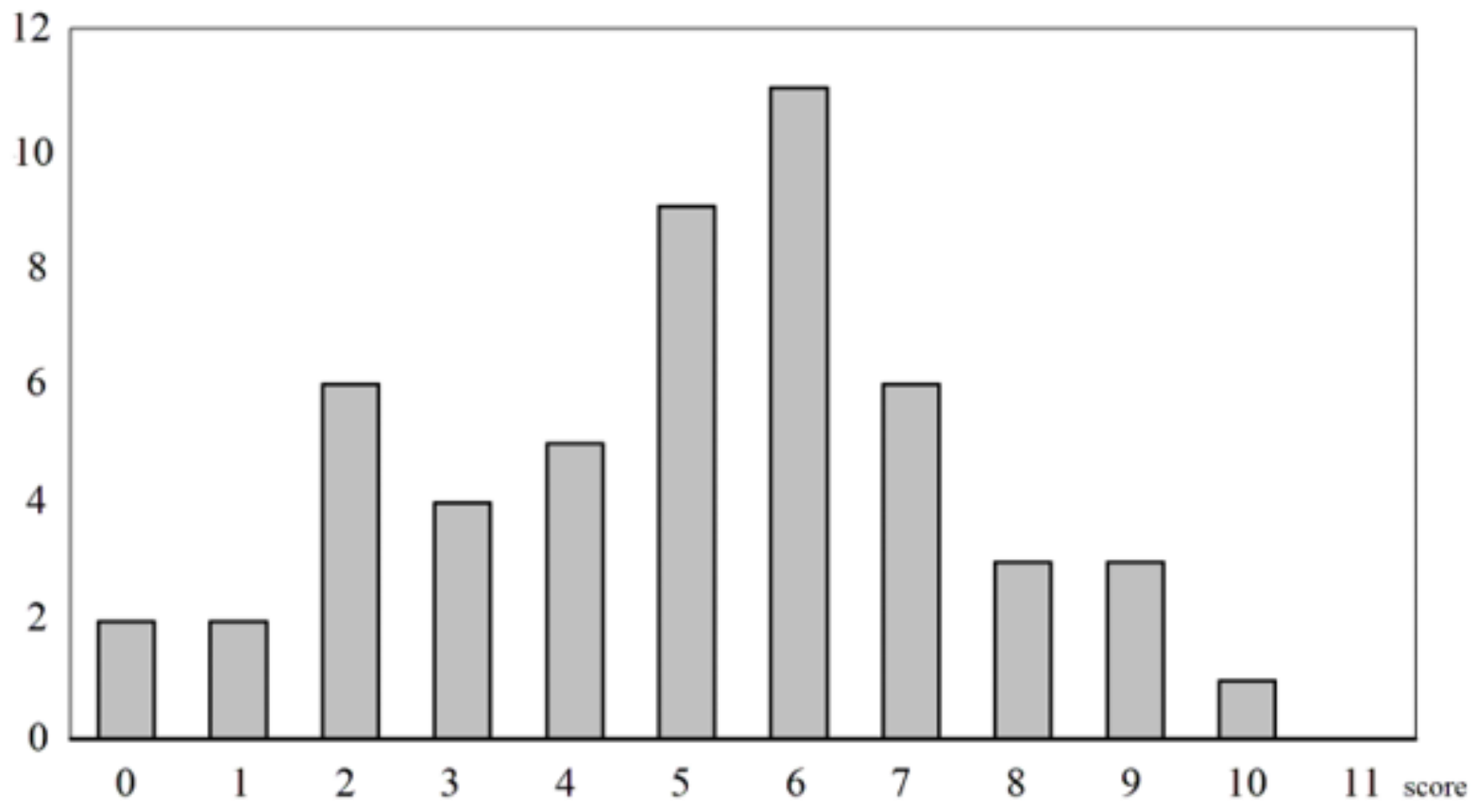

Figure 1

Distribution of the Career Success Scale scores of successful EBPS Part 2 respondents. 


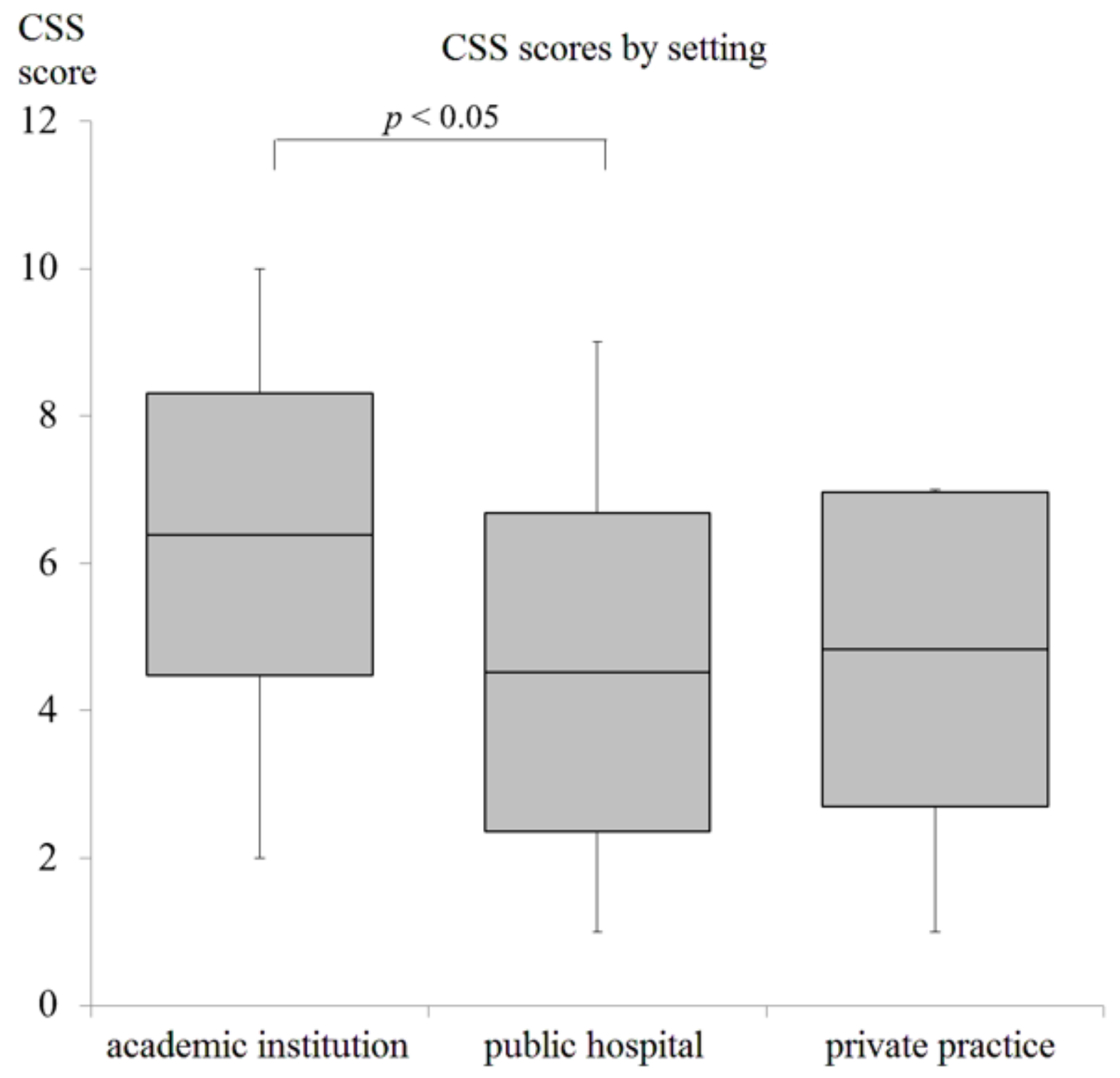

Figure 2

Career Success Scales of successful EBPS part 2 passing candidates by type of professional employment setting (academic versus public versus private practice).

\section{Supplementary Files}

This is a list of supplementary files associated with this preprint. Click to download.

- STROBEchecklistcohort.doc 